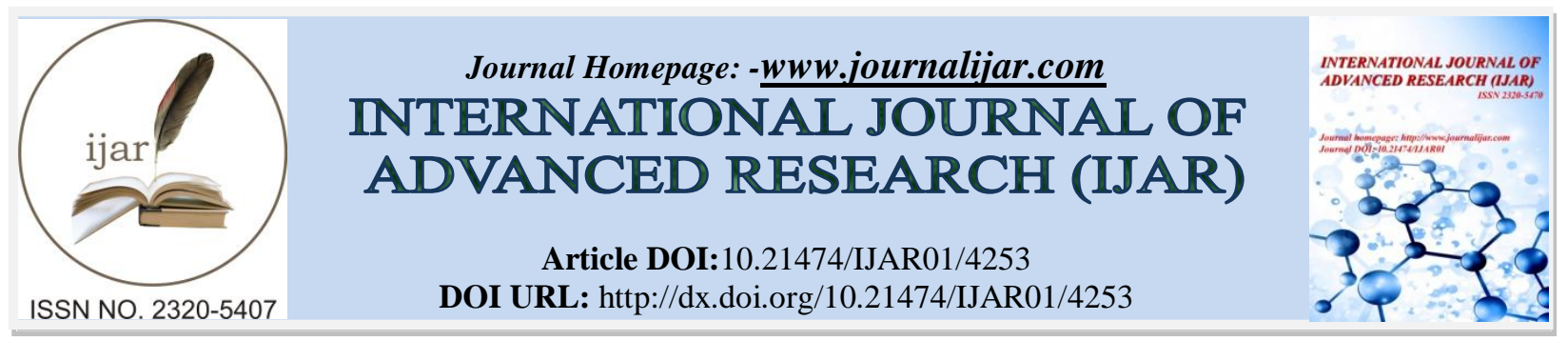

RESEARCH ARTICLE

\title{
SYNTHESIS \& CHARACTERIZATION OF NICKEL OXIDE NANOPARTICLES BY USING CO- PRECIPITATION METHOD.
}

*Pooja Khandagale and Dipali Shinde.

Department of Environmental Science, New Arts, Comm. \& Science College, Ahmednagar 414001.

\section{Manuscript Info}

Manuscript History

Received: 26 March 2017

Final Accepted: 29 April 2017

Published: May 2017

Key words:-

Co-Precipitation Method, Nanoparticles, XRD, FTIR, SEM, TEM EDAX etc

\section{Abstract}

In the present work Nickel oxide nanoparticles were Synthesized using Co-Precipitation method .It is simple and cost effective method .Nickel chloride hexahydrated was used (as a starting material)\& ammonia solution was used for this synthesis. The prepared nanoparticles of metal oxide (Nio) were characterized by using XRD,SEM,TEM,FTIR\&EDAX. The average particle size ,crystalline structure were estimated using XRD Analysis. The structural functional groups \&optical characters were analyzed by using SEM, FTIR \& UV-Visible Techniques. EDAX spectrum that showed the elemental composition of Nickel oxide, FTIR Showed the functional groups present in the synthesized Nickel oxide Nanoparticles.TEM Results confirmed the synthesis of nickel oxide nanoparticles.

This simple \& cost effective synthesis method will be useful for different industries for the preparation of Nickel oxide nanoparticles. In future this synthesized nanoparticle will be useful for photocatalytic Degradation of toxic dyes.

Copy Right, IJAR, 2017,. All rights reserved.

\section{Introduction:-}

Nanotechnology is the science of production \& use of nanosized materials to produce novel products \&process.(L.Alan porter et al,2008),Metal oxide Nanomaterial exihibit significantly chemical,mechanical,electronic,thermal,magnetic,catalytic properties \& optical properties in comparision with their bulk concentrates \& have extensively attracted application.(Q.Li,L-s et al 2007)\& (X.Xin,et al 2007).Nickel Oxide (Nio) already has received much attention due to its excellent electrical ,magnetic\& catalytic properties.(N.R.Jana,et al 2004).for the preparation of metal oxide nanoparticles many techniques have been used such as Sol-gel method, ultrasonic radiation ,pyrolysis, hydrothermal synthesis precipitation-calcintion method, leser chemical method, solid state method, Co-Precipitation method.(X.Y.Deng \& Z.chen et al 2004 , V.R.R.Pulimi \& P.Jeevanandam J 2009).

The key applications of nickel oxide nanoparticles are as follows:-

- In preparation of nickel cermet for the anode layer of solid oxide fuel cells

- In lithium nickel oxide cathodes for lithium ion micro batteries

- In electrochromic coatings, plastics and textiles

- In nanowires, nanofibers and specific alloy and catalyst applications

- As a catalyst and as anti-ferromagnetic layers

- In light weight structural components in aerospace

Corresponding Author:-Pooja Khandagale.

Address:-Department of Environmental Science, New Arts, Comm. \& Science College,Ahmednagar 414001. 
- Adhesive and coloring agents for enamels

- In active optical filters

- In ceramic structures

- In automotive rear-view mirrors with adjustable reflectance

- In cathode materials for alkaline batteries

- Electro chromic materials

- Energy efficient smart windows

- P-type transparent conductive films

- Materials for gas or temperature sensors, such as $\mathrm{CO}$ sensor, $\mathrm{H}_{2}$ sensor, and formaldehyde sensors

- As a counter electrodes [Source: AZo Nano]

Chemical Properties:-

\begin{tabular}{|l|l|}
\hline Chemical symbol & \multicolumn{1}{|c|}{$\mathrm{NiO}$} \\
\hline CAS. NO & $1313-99-1$ \\
\hline Group & Nickel 4 Oxygen16 \\
\hline Electronic configuration & Nickel[Ar] $3 \mathrm{~d}^{8} 4 \mathrm{~s}^{2}$ Oxygen[He] $2 \mathrm{~s}^{2} 2 \mathrm{p}^{4}$ \\
\hline CHEMICAL COMPOSITION & \\
\hline Element & Content $[\%]$ \\
\hline Nickel & 78.55 \\
\hline Oxygen & 21.40 \\
\hline
\end{tabular}

Physical Properties:-

The physical properties of nickel oxide nanoparticles are given in the following table:

\begin{tabular}{|l|l|l|}
\hline Properties & Metric & Imperial \\
\hline Density & $6.67 \mathrm{~g} / \mathrm{cm}^{3}$ & $0.240 \mathrm{lb} / \mathrm{in}^{3}$ \\
\hline Molar mass & $74.71 \mathrm{~g} / \mathrm{mol}$ & \\
\hline
\end{tabular}

Thermal Properties:-

The thermal properties of nickel oxide nanoparticles are in the following table :

\begin{tabular}{|l|l|l|}
\hline Properties & Metric & Imperial \\
\hline melting point & $1955^{\circ} \mathrm{c}$ & $3551^{\circ} \mathrm{c}$ \\
\hline
\end{tabular}

The Co-Precipitation method used for the synthesis of Nio Nanoparticles is simple \& cost effective Method.In the present study is focused on synthesis of Nio nanoparticles using Co-Precipitation method with nickel chloride hexahydrated(as a basic material)\& ammonia solution as precipitating material. The samples were characterized by FTIR, XRD, SEM, TEM \& EDAX.

\section{Experimental:-}

Materials Methods:-

Nickel chloride hexahydrated \&Ammonia solution were used for this experiment. All chemical used were of AR Grade brought from quialigens fine chemicals a division of GlaxoSmithKline pharmaceuticals limited Mumbai), \& deionised water used for the preparation of solutions.

\section{Synthesis of Nickel Oxide nanoparticle:-}

In this synthesis $26.4 \mathrm{~g}$ of Nickel chloride mix with $100 \mathrm{ml}$ of deionized water, Then $\mathrm{NH}_{4} \mathrm{OH}$ solution was injected to the above solution at $25^{\circ} \mathrm{C}$ under constant stirring, and the resulting mixture was kept at the room temperature for $24 \mathrm{hrs}$ for aging.

After the reaction was complete, the resulting light-green solution was filtered, and then washed with deionized water and ethanol for 5-10 times to remove the by-products or impurities, and dried in air at $100^{\circ} \mathrm{C}$ for $4 \mathrm{hr}$.The assynthesized material was calcinated at $600^{\circ} \mathrm{C}$ for $4 \mathrm{hrs}$ and $6 \mathrm{hrs}$ in air to obtain nanoparticles. 


\section{Characterization:- \\ XRD, SEM, FTIR, TEM \&EDAX.}

The size, structure \& Morphology of metal oxide nanoparticles were characterized by FTIR .This Spectra of Nio NP's were recorded using(FTIR-180 Simadzu spectrophotometer) with $\mathrm{KBr}$ powder technique in the wavelength range 400-4000 cm-1,XRD (D8 Bruker with CuK radiation=1.5406 A0 in the range of 2theta degree 20-80),SEM (Scanning electron machine model-JEOL JSM 6360),TEM (Transmission Electron Microscopy was carried out using JEOL-3010)\& EDAX( Energy Dispersive x-ray spectroscopy), this spectrum shows the elemental composition of Nickel oxide

\section{Result and Discussion:-}

\section{Synthesis of Nickel Oxide nanoparticle:-}
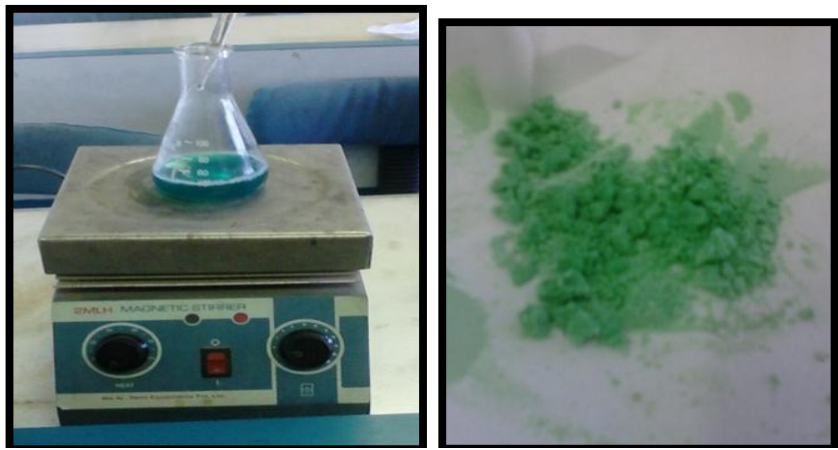

Fig.1:-Synthesis of $\mathrm{NiO}$ nanoparticles: $\quad$ Fig.2:- $\mathrm{NiO}$ nanopowder

From above figure, it observed that addition of ammonia solution in nickel chloride after stirring it becomes homogeneous and formation of green precipitate indicate formation of nickel oxide nanoparticle.

\section{X-ray Diffraction study:-}

The prepared nanoparticles were characterized by powder X-ray diffractometer; fig. 3 shows that X-Ray diffraction spectrum of $\mathrm{NiO}$ samples. The XRD Results showed that prepared powder was Amorphous in nature. The pattern has number of impurity peaks so unable to identify characteristics peak of Nio.Hence unable to calculate the crystalline size.

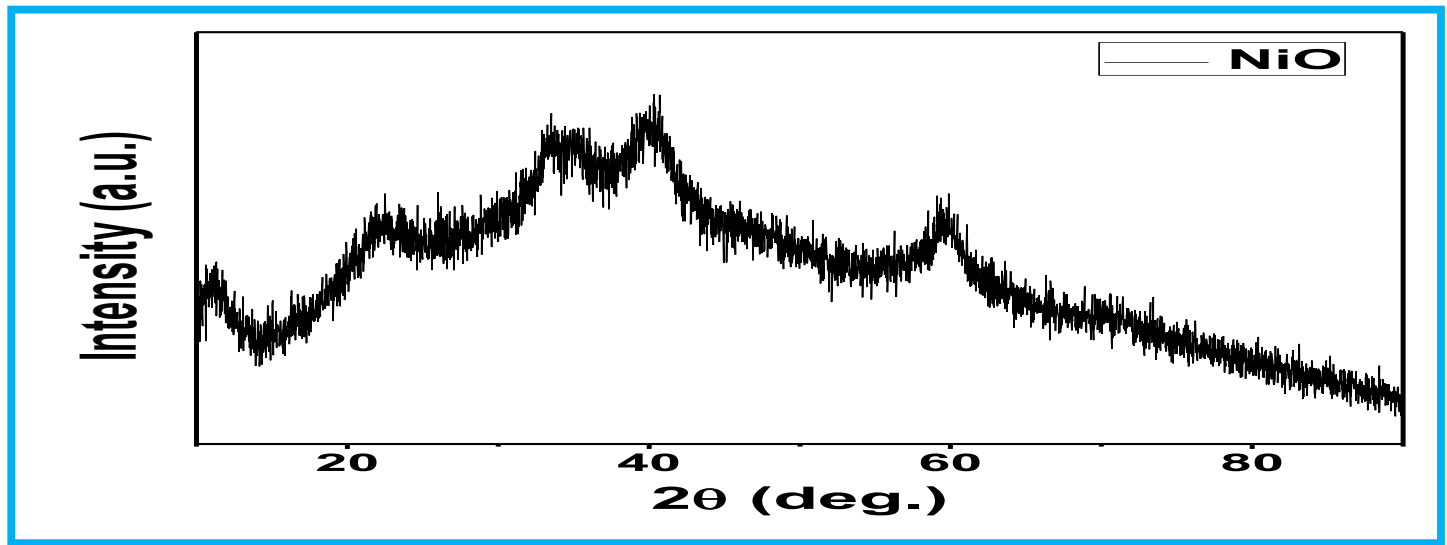

Fig.3:-XRD Analysis Pattern of structure of $\mathrm{NiO}$ is Amorphous in nature.

\section{SEM Analysis:-}

Scanning electron microscopy is widely used to study the morphological features and surface characteristics of photo catalyst materials.The surface morphological features of synthesized nanoparticles were studied by SEM Technique. Fig 4 shows the SEM image of Nio nanoparticles with magnification $100 \mathrm{Kx} \&$ particles was approximately in the range of 100-500 $\mathrm{nm}$. The instrumental Parameter, accelerating voltage, SEM magnification \& working diastance are indicated on image. The result indicate that occurrence of particle is Rod shape \& highly agglomerated. 

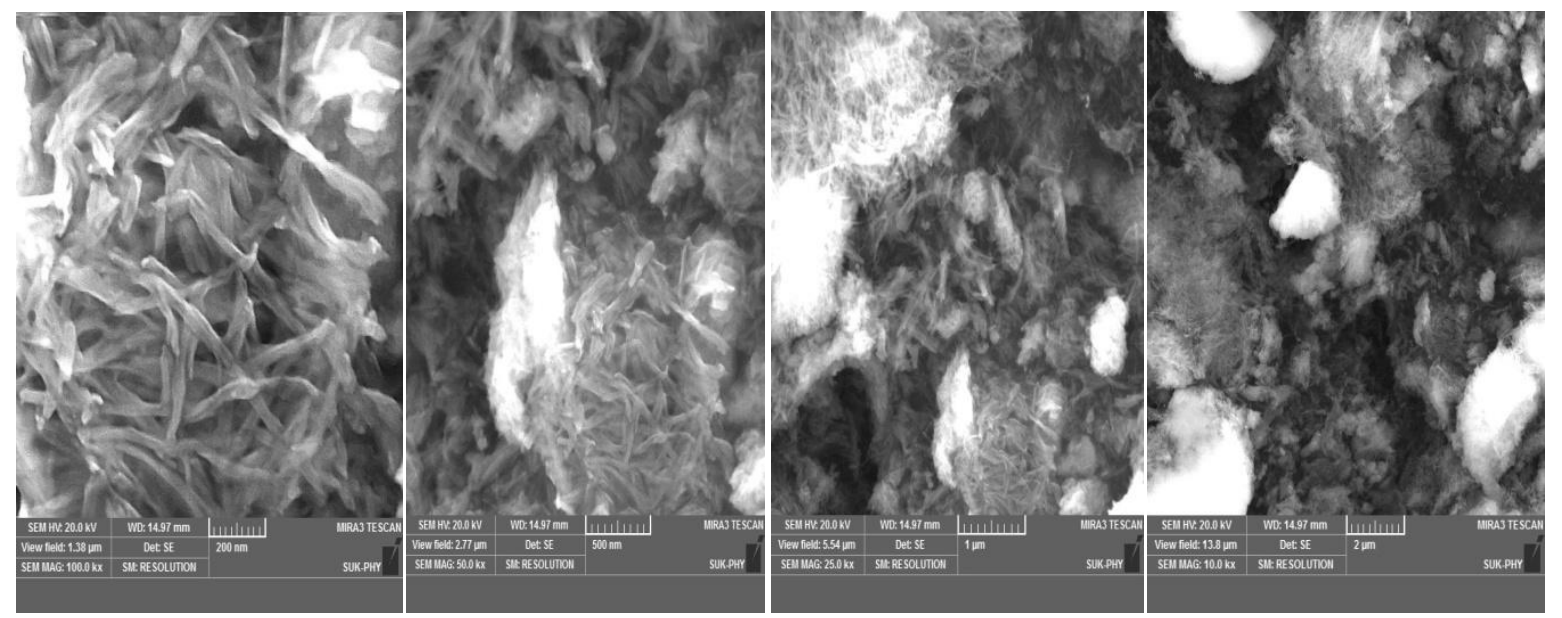

Fig.4:-SEM image of NiO Nanoparticles

\section{TEM Analysis:-}

The Transmission Electron microscopic analysis was carried out to confirm the actual size of particles, their growth pattern and distribution of the crystalline. This result showed that the particle size of Nanoparticles were found to be range is $\mathbf{3 1 . 8 7} \mathrm{nm}$.TEM Results also confirm the Synthesis of Nio NP's.

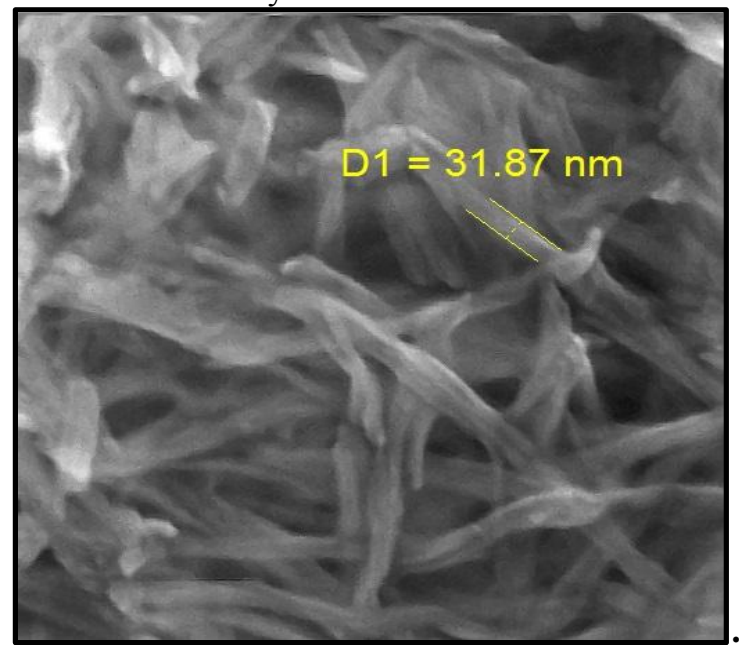

EDAX Analysis:-

Fig. 5:- TEM Image of the prepared NiO Nanoparticles.

The quantitative Compositional analysis of $\mathrm{NiO}$ Nanoparticles was carried out using Energy dispersive X-ray (EDAX) spectroscopy measurement .The EDAX analysis also confirm the presence of NiO NP's (Fig.6). The presence of impurities with nickel oxide nanoparticles are also confirmed by EDAX analysis and it was given in Table 1.

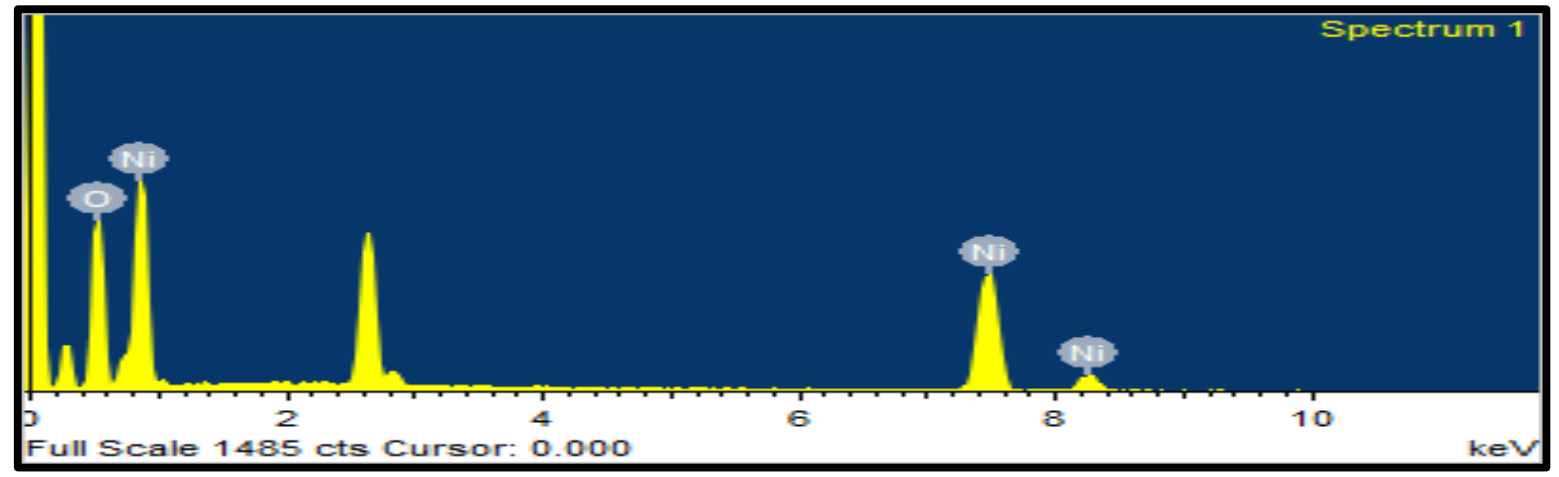

Fig. 6:- EDAX Spectrum of NiO Nanoparticles. 
Spectrum processing : Peaks possibly omitted : 2.628, 2.841, $6.105 \mathrm{keV}$ Processing option : All elements analyzed (Normalised) Number of iterations $=3$

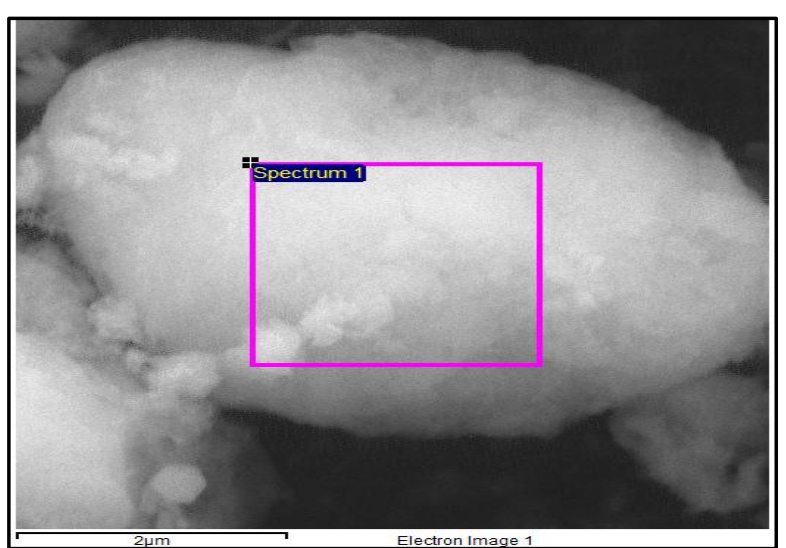

\begin{tabular}{|l|l|l|}
\hline Element & Weight\% & Atomic\% \\
\hline \hline O K & 37.45 & 68.72 \\
\hline Ni K & 62.55 & 31.28 \\
\hline & & \\
\hline Totals & 100.00 & \\
\hline
\end{tabular}

Table 1- EDAX analysis of element $\mathrm{NiO}$

Fig. 7:- EDAX image of NiO Nanoparticles

FTIR Analysis:-

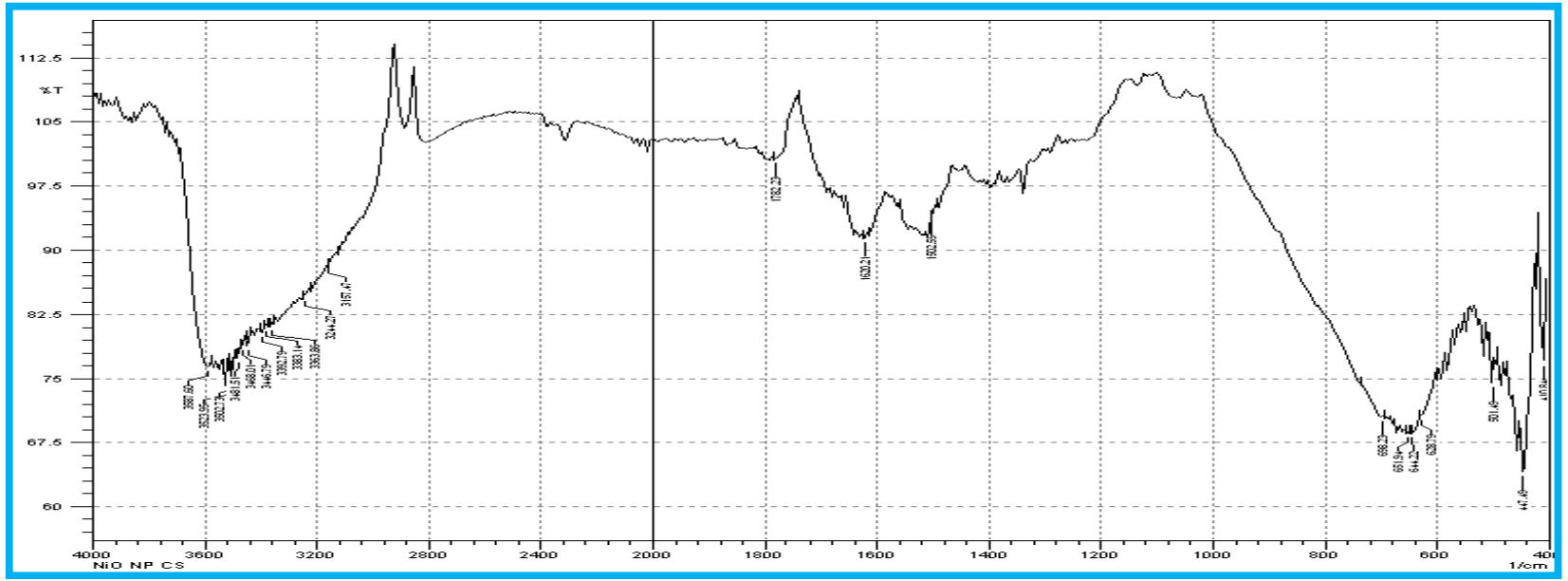

Fig 8 :-.FTIR analysis pattern of Nio nanoparticles

Indicates the FTIR spectra of NiO Nanoparticles in the range of 700-400 $\mathrm{cm}^{-1}$, The FTIR spectrum shows the characteristic peak at $410.84 \mathrm{~cm}^{-1}, 447.49 \mathrm{~cm}^{-1} 459.06 \mathrm{~cm}^{-1}, 482.20 \mathrm{~cm}^{-1}, 501.49 \mathrm{~cm}^{-1} 516.92 \mathrm{~cm}^{-1}, 547.78 \mathrm{~cm}^{-1}$ $628.79 \mathrm{~cm}^{-1}, 651.94 \mathrm{~cm}^{-1}, 698.23 \mathrm{~cm}^{-1}$. FTIR spectrum of $\mathrm{NiO}$ nanoparticle showed significant absorption peak at $447.49 \mathrm{~cm}^{-1}$ is due to Co-O stretching vibration mode.

\section{Conclusion:-}

The present study reported on Nickel oxide nanoparticles have been successfully synthesized by co-precipitation method(using nickel chloride \& ammonia).The synthesized nanoparticles were characterized by XRD,SEM,TEM,FTIR \&EDAX Analysis. The SEM Result confirmed that synthesized nanoparticles were in rod shape. From TEM result the particle size of Nanoparticles were found to be range is $31.87 \mathrm{~nm}$. TEM Results also confirmed the Synthesis of Nio NP's.

The FTIR Spectrum confirmed the presence of Nio nanoparticles. The elemental nickel \& oxide molecules are confirmed by EDAX Analysis.

This simple \& cost effective synthesis method will be useful coming for different industries for the preparation of Nickel oxide Nanoparticles. In future this synthesized Nanoparticle will be used for photocatalytic Degradation of toxic dyes. 


\section{Acknowledgements:-}

The Author's thanks to principle of New arts,comm. \& Science college Ahmednagar,Affiliated to Savitribai Phule Pune university,Pune,Dr.S.D.Kulkarni Head of the Dept of Environmental Science For providing Necessary Facilities for project Work.

\section{References:-}

1. N.R.Jana, Y.f.chen \& X.G.Peng:Chem.mater.16 (2004)39313935

2. X.Y.Deng and Z.Chem:Mater.Lett.58 (2004)276-280

3. Q.Li,L.-S,Wang,B.-Y.Hu,c Yang,L.Zhou,and L.Zhang, Preparation \& characterization of nanoparticles through calcinations of malategel,"materials Letters,vol.61,no.8-9,pp.1615-1618,2007.

4. X.Xin,Z.Lu,B-Zhou,et al .,effect of synthesis conditions on the performance of weakly agglomerated nanocrystalline,"Journal of Alloys and compounds,vol,no.1-2,pp.251-255,2007

5. L.Alan porter,J.youtie,S.philip,J.David Schoeneck Refining search terms for nanotechnology,.J Nanopart Res.2008;10:715-728

6. V.R.R.Pulimi and P.Jeevanandam :J.Magn.Mater,321(2009)2556-2562

7. Rajesh kumar,Ashwani Sharma,Nawal Kishore,Narendra Budhiraja ,International journal of Engineering,Applied and Management Sciences Paradigms, vol.06,Issue 01,August 2013.

8. Manisha,Neetu,Synthesis \& Characterization of NICKEL OXIDE NANOPARTICLES BY SOL-GEL METHOD, vol.No 5 Issue No.08,Aug 2016 